\title{
Convivium (1986), de Harry Crowl
}

\author{
Harry Crowl, Antonio R. Spoladore Hurtado \\ Universidade Federal do Paraná| Brasil
}

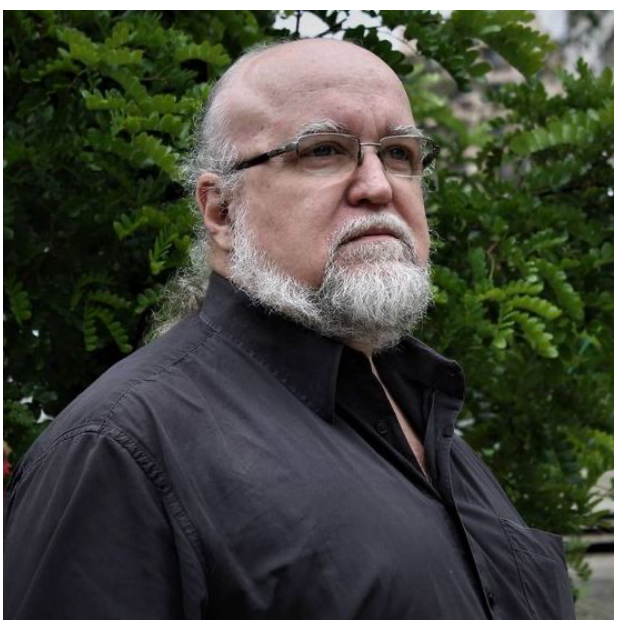

Nascido em Belo Horizonte, em 1958, Harry Crowl é compositor e musicólogo radicado em Curitiba desde 1994. Estudou Música, Letras e Semiótica no Brasil e, nos EUA, estudou Composição na Juilliard School of Music. Em seu catálogo há, atualmente, cerca de 200 obras musicais, das quais constam de todos os gêneros instrumentais e vocais, incluindo música para cinema e teatro. Sua música tem sido executada em público, transmitida em programas de rádio e plataformas digitais no Brasil e em todo o mundo. Vários grupos internacionais, orquestras e solistas já tocaram e encomendaram obras de sua autoria.

Entre os prêmios recebidos destacam-se, "Encomenda de Obra”, 2012 e 2014, da FUNARTE, para os quais escreveu "Mirabilis Jalapa”, estreado na XXa Bienal de Música Brasileira Contemporânea, no Rio de Janeiro, em 2013, e, "Elogio da Sombra”, para clarone e orquestra de cordas, estreada na XXI - Bienal, em 2015. Trabalhou como pesquisador de música do período colonial em Ouro Preto, MG, junto à Universidade Federal de Ouro Preto. Foi Professor da Escola de Música e Belas Artes do Paraná/UNESPAR até 2019. É Diretor Artístico da Orquestra Filarmônica da UFPR. Produz e apresenta semanalmente programas para a Rádio Paraná Educativa FM. 


\section{1 obra Convivium foi composta entre 1985 e 1986 pelo compositor Harry Crowl, sendo a única obra puramente eletroacústica no catálogo de obras do compositor. Em sua 1 concepção, foram utilizadas gravações de origem étnica oriundas de países tidos como} do Terceiro Mundo, além de alguns sons eletrônicos. Como consequência da escassez de recursos para compor e da influência de uma corrente estética inspirada no cinema novo brasileiro, Convivium foi composta com o mínimo de recursos possível (HURTADO; CROWL, 2020). Com isso, seu processo composicional durou quase dois anos e foi artesanal, envolvendo, em grande parte, recortes e manipulações de fitas magnéticas. Já os sons puramente eletrônicos foram utilizados como elementos de ligação entre as gravações manipuladas (HURTADO; CROWL, 2020). A partir dessas gravações, o compositor manipulou os sons e buscou pontos em comum entre eles com o intuito de construir um "grande painel”, um "grito” do Terceiro Mundo.

Muito por conta de seu trabalho em Ouro Preto com pesquisa e reconstituição de música colonial brasileira do final do século XVIII e início do século XIX, Harry Crowl sempre percebeu a importância da preservação. Trabalhando com a música colonial, ele enfrentou alguns dos desafios da preservação da música em papel, principalmente decorrentes da umidade. Essa preocupação, segundo o compositor, também se estendia a outros meios (HURTADO; CROWL, 2020). Em decorrência disso, sua obra eletroacústica foi gravada em uma fita de rolo da Sony de alta resistência e está guardada em local mais seco possível desde 1986.

A cópia original da obra foi digitalizada pela primeira vez no ano de 1996, no laboratório de pesquisas sonoras da PUC de São Paulo, durante o mestrado de Harry em Comunicação e Semiótica. Nesse processo, o áudio foi equalizado e restaurado (HURTADO; CROWL, 2020). A segunda digitalização foi realizada no estúdio do compositor Felipe Ayres, no dia 18 de dezembro de 2020. A partir desta nova digitalização, percebemos que a fita estava em bom estado de preservação; havia, contudo, um ruído elétrico contínuo no canal esquerdo, um desequilíbrio de amplitude entre os canais e uma pequena falha no canal direito entre os minutos 12:04 e 12:12. O intuito dessa nova digitalização foi averiguar a qualidade da fita após quase 35 anos desde a sua gravação e manter uma cópia da peça original sem as alterações de 1996, em alta qualidade de amostragem e resolução $96 \mathrm{kHz}$ e $24 \mathrm{bit}$. Ambas cópias digitais estão disponíveis para preservação nos servidores da Revista Vórtex: 
http://vortex.unespar.edu.br/crowl_1996.wav

http://vortex.unespar.edu.br/crowl 2020.wav

\section{AUTOR}

Antonio R. Spoladore Hurtado (1996 -) é mestrando na área de Composição Musical pela Universidade Federal do Paraná (UFPR), sob orientação de Felipe de Almeida Ribeiro. Possui graduação em Produção Sonora e Criação Musical, também na Universidade Federal do Paraná, no ano de 2018. Desenvolve pesquisas sobre composição musical, música eletroacústica e áudio, com ênfase em processos composicionais e preservação e performance de música eletroacústica. Estudou composição com Felipe Ribeiro, Roseane Yampolschi, Clayton Mamedes, Indioney Rodrigues e Maurício Dottori. Atua como compositor, produtor musical, guitarrista, professor e pesquisador. ORCID: https://orcid.org/0000-0003-0474-582X. E-mail: antoniospoladore.hurtado@gmail.com

\section{REFERÊNCIAS}

CROWL, Harry; HURTADO, Antonio R.S. Entrevista com Harry Crowl. Revista Vórtex, Curitiba, v.9, n.1, p. 1-11, 2021.

CROWL, Harry. Convivium. Curitiba: UFPR, 2020. Arquivo digital.

CROWL, Harry. Convivium. São Paulo: PUC-SP, 1996. Arquivo digital. 